\title{
Major Adverse Cardiovascular Events After Implantation of Absorb Bioresorbable Scaffold: One-Year Clinical Outcomes
}

\author{
Tanja Šobot, ${ }^{1}$ Nikola Šobot, ${ }^{2}$ Zorislava Bajić, ${ }^{1}$ Nenad Ponorac, ${ }^{1}$ Rade Babić ${ }^{3}$
}

\section{Abstract}

Background/Aim: Bioresorbable vascular scaffold (BVS) represents a novel generation of intracoronary devices designed to be fully resorbed after healing of the stented lesion, delivering antiproliferative drug to suppress restenosis, providing adequate diameter of the coronary vessel and preserving the vascular endothelial function. It was supposed that BVS will reduce neointimal proliferation and that their late bioresorption will reduce the negative effects of traditional drug-eluting stents, including the late stent thrombosis, local vessel wall inflammation, loss of coronary vasoreactivity and the need for the long-term dual antiplatelet therapy.

The purpose of this research was to investigate efficacy and safety of Absorb everolimus-eluting BVS implantation and the prevalence of major adverse cardiovascular events (MACE) at the mid-term follow-up.

Methods: The study encompassed 42 patients selected for BVS implantation and fulfilling inclusion criteria - 37 male and 5 female - admitted to the Dedinje Cardiovascular Institute, Belgrade, Serbia over the one-year period (from January 2015 to January 2016) for percutaneous coronary intervention (PCI). Coronary vessel patency before and after stenting was assessed by the Thrombolysis in Myocardial Infarction flow (TIMI) grades.

After the index PCI procedure with BVS all patients were clinically followed by regular (prescheduled or event-driven) visits during the next 12-month period.

Results: In the intention-to-treat analysis, all Absorb BVS procedures were successful, without the need for conversion to other treatment modalities. The complete reperfusion (TIMI flow grade 3) after the intervention was established in $97.6 \%$ of patients and $100 \%$ of them achieved the TIMI flow grade $\geq 2$.

The presence of angina pectoris was reduced significantly by the BVS procedure: stable angina $57.1 \%$ to $11.9 \%$, ( p < 0.001) and unstable angina $31 \%$ to $0 \%$, respectively $(\mathrm{p}<0.001)$. After the one-year follow-up, the MACE rate was $11.9 \%$. Myocardial infarction occurred in $4.8 \%$ and the need for PCI reintervention in $2.4 \%$ of cases (not influenced by the gender or the age of patients). There were 4 cases of death (all patients were older and had lower values of left ventricular ejection fraction).

Conclusion: The results of the current research demonstrated a high interventional success rate of the Absorb BVS implantation, followed by the early improvement of the anginal status. However, that was not translated into the favourable mid-term clinical outcomes, opening debate about the current status of Absorb BVS and the need for future refinements of stent design and implantation techniques.

Key words: Absorb everolimus-eluting bioresorbable vascular scaffold; Percutaneous coronary intervention; Major adverse cardiovascular events; Thrombolysis in Myocardial Infarction (TIMI) flow grade.
(1) Department of Physiology, Faculty of Medicine, University of Banja Luka, Banja Luka, the Republic of Srpska, Bosnia and Herzegovina.

(2) Clinic for Cardiovascular Diseases, University Clinical Centre of Republic of Srpska, Banja Luka, the Republic of Srpska, Bosnia and Herzegovina.

(3) Dedinje Cardiovascular Institute, Belgrade, Republic of Serbia.

Correspondence: NIKOLA ŠOBOT dr.shobot@gmail.com

\section{ARTICLE INFO}

Received: 16 October 2021 Revision received: 13 December 2021 Accepted: 14 December 2021

Copyright $\odot 2021$ Šobot et al. This is an open access article distributed under the Creative Commons Attribution License (CC BY), which permits unrestricted use, distribution and reproduction in any medium, provided the original work is properly cited. This article should be cited as follows: Šobot T, Šobot N, Bajić Z, Ponorac N, Babić R. Major adverse cardiovascular events after implantation of absorb bioresorbable scaffold: one-year clinical outcomes. Scr Med 2021 Dec;52(4):249-57. 


\section{Introduction}

Ischaemic coronary artery disease is the most important part the cardiovascular pathology and is considered to be among the most frequent causes of the global mortality. It includes chronic (stable) ischaemic heart disease and acute coronary syndromes (ACS). ${ }^{1}$

Percutaneous coronary intervention (PCI) is one of the most frequently utilised interventions for the reestablishment of blood flow in the clogged artery. It is used to open the stenosed or occluded coronary vessel by the balloon inflation and finally to implant a coronary stent to ensure that it remains open. However, stent implantation can initiate negative effects, including plaque crushing, injury of vascular endothelium and stretching and lacerations of the vessel wall, which can lead to coronary restenosis. ${ }^{2}$ The phenomenon of an elastic recoil, along with the constrictive remodelling and neointimal proliferation is involved in the mechanism of restenosis as well. Therefore, the motivation for developing different types of stents was generated in order to reduce restenosis and stent thrombosis, as well as to entirely restore the vascular function and physiology. ${ }^{3}$ Dual antiplatelet therapy (DAPT) is mandatory in PCI procedures to avoid thrombotic complications and to reduce the device-related short- and longterm adverse events. ${ }^{4}$ DAPT consists of the combination of acetylsalicylic acid (ASA) and an oral inhibitors of platelet $\mathrm{P} 2 \mathrm{Y}_{12}$ receptor for adenosine 5'-diphosphate. ${ }^{5}$

There are three types of vascular scaffolds available: bare-metal (BMS), drug eluting metallic (DES) and bioresorbable (BRS) stents. So far, the gold standard for PCI is a metallic drug eluting stent. However, the late adverse events (restenosis, stent thrombosis and neoatherosclerosis) have initiated the current research into the development of BRS stents. ${ }^{6}$

The Absorb everolimus-eluting bioresorbable vascular scaffold (BVS, Abbott Vascular) is a novel device, an alternative to DES for PCI, aimed to decrease the incidence of late adverse clinical events following the coronary stenting (restenosis and stent thrombosis). As a new generation of intracoronary devices, BVS are designed to be fully resorbable, providing adequate diameter and function of blood vessel and delivering a drug without permanent implant in the body. ${ }^{7}$
BVS comprises of crystalline backbone struts (150 $\mu \mathrm{m}$ thick) of poly-L-lactide coated with a 1:1 mixture of poly-D-L-lactide (resorbable polymer functioning as drug carrier) and the antiproliferative drug everolimus. ${ }^{6,8}$ The mechanical support of the stent itself solves an initial problem of acute recoil following balloon angioplasty. Furthermore, everolimus elution reduces neointimal proliferation and stents' late bioresorption reduces the adverse events following the traditional drug eluting stents including late stent thrombosis, local inflammation, loss of coronary vasoreactivity and the need for long-term dual antiplatelet therapy. ${ }^{9}$ However, in the present clinical scenario, BVS were accompanied by a high incidence of scaffold thrombosis during the first twelve months after implantation. ${ }^{10}$ Further analyses have suggested that the risk of thrombosis closely correlates with the greater width and thickness of BVS struts compared to DES, associated with disturbed local blood flow and consequent platelet aggregation. Thrombotic risk is higher in the vessels with small referent diameter, as well as the ones with the small achieved final minimal lumen diameter at the end of the PCI procedure. Implantation techniques and discontinuation of DAPT increase the thrombotic risk, as well. ${ }^{11}$ Accordingly, to the current recommendation, DAPT should be continued for at least one year after $\mathrm{PCI}^{12}$ what the patients were instructed to follow as well.

Major adverse cardiac events (MACE) are a composite of several adverse clinical outcomes, so that they may have broad and often overlapping definitions. Generally, MACE includes various components such as myocardial infarction, cardiac death, any-case sudden death, need for the repeated revascularisation, either percutaneous (PCI) or surgical coronary artery bypass grafting (CABG), re-hospitalisation due to cardiovascular problems, cerebrovascular insult, recurrent angina, worsening of heart failure. ${ }^{13-15}$ Because of such variety of MACE definitions, the reported total MACE rates may differ in individual publications ${ }^{16}$ In the current study, MACE was defined as a composite of myocardial infarction, re-hospitalisation for the need of coronary revascularisation (PCI or CABG) and death of all causes.

The purpose of this research was to investigate Absorb BVS implantation safety, immediate efficacy and the mid-term (one-year) clinical outcomes. 


\section{Methods}

The research was conducted at the Dedinje Cardiovascular Institute, Belgrade, Serbia over the period of one year (from January 2015 to January 2016) on patients admitted for percutaneous revascularisation. A total of 42 patients with both stable and unstable angina pectoris met the inclusion criteria. PCI was performed exclusively with Absorb BVS, Abbott Vascular, Santa Clara, California, USA. Inclusion criteria for Absorb BVS implantation were the age of 18 years and above, clinical presence of angina pectoris, both sexes and the reference vessel diameter at the targeted lesion between 2.5 to $3.9 \mathrm{~mm}$ determined by quantitative coronary angiography (QCA). The patients who were included in this study were not the only patients who underwent implantation of Absorb BVS at the Dedinje Cardiovascular Institute.

The decision to limit the vessel size was based upon the concern about the higher rates of stent thrombosis in small vessels, what was confirmed in the later clinical studies. ${ }^{17}$ Patients with acute coronary syndromes and patients with prior coronary interventions were included in the study as well. Patients with a need for a combination of drug-eluting stent and BVS in the same procedure were excluded. Throughout the interventional procedure, all patients were treated with heparin/enoxaparin.

Patients were preloaded with DAPT according to standard protocol and such treatment was continued for 12 months following the intervention (ASA $100 \mathrm{mg}$ and clopidogrel $75 \mathrm{mg}$ daily). Coronary vessel patency before and after stenting was assessed by the Thrombolysis in Myocardial Infarction flow (TIMI) grades, applying the standard definitions. ${ }^{18}$

The local Ethical Committee of Dedinje Cardiovascular Institute approved this research project and informed consent was obtained from each patient. Being a part of N.S. cardiology graduation thesis, this endeavour was endorsed by the Medical Faculty, University of Belgrade as well.

During the 12-month follow-up, all patients were followed-up prospectively and systematically by phone at one, six and twelve months after the intervention for clinical evaluation and were seen in the office if medically indicated as well. Event or patient-driven visits were provided as well.
The incidence of MACE onset was monitored methodically over the whole follow-up period.

For statistical analysis, patient data were extracted from the hospital information system to a Microsoft Excel database. Final data analysis was performed using SPSS software (IBM SPSS Statistics for Windows, Version 21.0. Armonk, NY: IBM Corp.). For descriptive statistics, continuous variables are presented as mean \pm standard deviation (SD) or as median with corresponding range, depending on the data distribution. The normality of sample distribution was analysed by the Kolmogorov-Smirnoff test. Nonparametric variables were presented as frequency distributions. For testing the hypothesis on the treatment effect Student's t-test for serial measurements, or Wilcoxon signed-rank test were used, depending on the normality of data distribution. Frequency distribution differences were assessed using Pearson's Chi-square test or Fisher's exact test, as indicated. A two-tailed probability level of $p<$ 0.05 was considered to indicate statistical significance.

\section{Results}

\section{Baseline characteristics}

The study included a total of 42 patients, 37 male (88.1\%) and 5 female (11.9\%). Their average age was $57.4 \pm 11.5$ (ranging from 34 to 82 years). Patients' characteristics collected from the medical history and clinical examination are presented in Table 1.

\section{Procedural details}

In the intention-to-treat analysis, all Absorb BVS procedures were successful, without the need for conversion to other treatment modalities. Pre-dilatation was performed in $66.7 \%$ and post-dilatation in $57.1 \%$ of patients. In the PCI procedure, 1 BVS stent was implanted in $83.3 \%$, 2 stents in $14.3 \%$ and 3 stents in $2.4 \%$ of cases. Concerning the stent dimensions used in the procedures, the predominant stent length was in the range of 16$25 \mathrm{~mm}(59.5 \%)$ and the predominant diameter was in the range of 3.0-3.9 mm (64.3\%). During the intervention, Absorb BVS stent overlap was done in $14.3 \%$ and spot stenting versus entire coverage was done in $4.8 \%$ of treated patients. Characteristics of BVS implanted and implantation techniques are presented in Table 2. 
Table 1: Baseline patients' characteristics

\begin{tabular}{lcc}
\hline Comorbidities & $\mathbf{n}$ & $\%$ \\
\hline Gender & 38 & 90.5 \\
\hline Male & 14 & 33.3 \\
\hline Female & & \\
\hline Prior cardiovascular interventions & 38 & 7.1 \\
\hline Coronary artery bypass graft (CABG) & 14 & 40.5 \\
\hline Percutaneous coronary intervention (PCI) & & \\
\hline Acute coronary syndromes & 23 & 54.8 \\
\hline Yes & 19 & 45.2 \\
\hline No & 24 & \\
\hline Angina pectoris & 13 & 37.1 \\
\hline Stable angina & & \\
\hline Unstable angina & 4 & 9.5 \\
\hline Left ventricular ejection fraction (LVEF) & 16 & 38.1 \\
\hline$<25 \%$ & 22 & 52.4 \\
\hline $26-45 \%$ & & \\
\hline$>46 \%$ & 7 & 16.7 \\
\hline Bifurcations lesions & 35 & 83.3 \\
\hline Yes &
\end{tabular}

Table 2: Characteristics of stents and implantation techniques

\begin{tabular}{lcc}
\hline Stents & $\mathbf{n}$ & $\%$ \\
\hline Number of implanted stents & 35 & 83.3 \\
\hline 1 & 6 & 14.3 \\
\hline 2 & 1 & 2.4 \\
\hline 3 & & \\
\hline Stent length (mm) & 6 & 14.3 \\
\hline to 15 & 25 & 59.5 \\
\hline 16 - 25 & 11 & 26.2 \\
\hline 26 and more & & \\
\hline Stent diameter (mm) & 15 & 35.7 \\
\hline $2.5-2.9$ & 27 & 64.3 \\
\hline $3.0-3.9$ & 0 & 0.0 \\
\hline 4.0 and more & 42 & \\
\hline Intervention & 28 & 66.7 \\
\hline Stent implanted & 24 & 57.1 \\
\hline Stent predilatation & & \\
\hline Stent postdilatation & 6 & 14.3 \\
\hline Implantation techniques & 2 & 4.8 \\
\hline Overlap & & \\
\hline Spot &
\end{tabular}

\section{Clinical outcomes}

Immediately after the intervention, the complete reperfusion (TIMI flow grade 3) was established in $97.6 \%$ of patients and $100 \%$ of them achieved TIMI flow grade $\geq 2$, as shown in Figure 1 . Regarding the immediate clinical efficacy of Absorb BVS stenting, the prevalence of stable angina (before and after PCI) was $57.1 \%$ vs $11.9 \%$, showing statistically significant reduction $\left(\chi^{2}\right.$ test $=14.44$, $\mathrm{p}<0.001$ ). Additionally, the prevalence of unstable angina before and after Absorb BVS stenting showed a significant decrease as well: $31 \%$ be- fore and $0 \%$ after the procedure $(\mathrm{p}<0.001)$. Immediate efficacy of Absorb BVS implantation on the improvement of anginal status is presented in Figure 2.

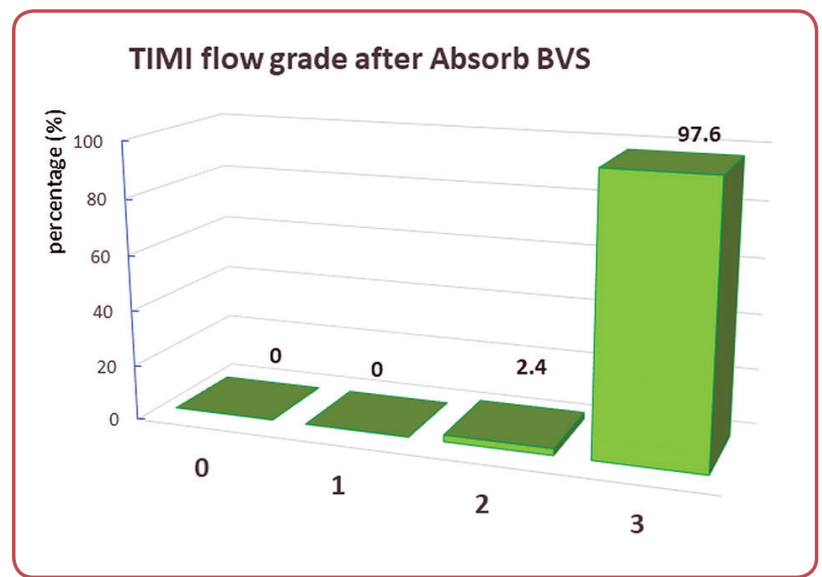

Figure 1: Results of Absorb BVS stenting: Distribution of achieved TIMI flow grades

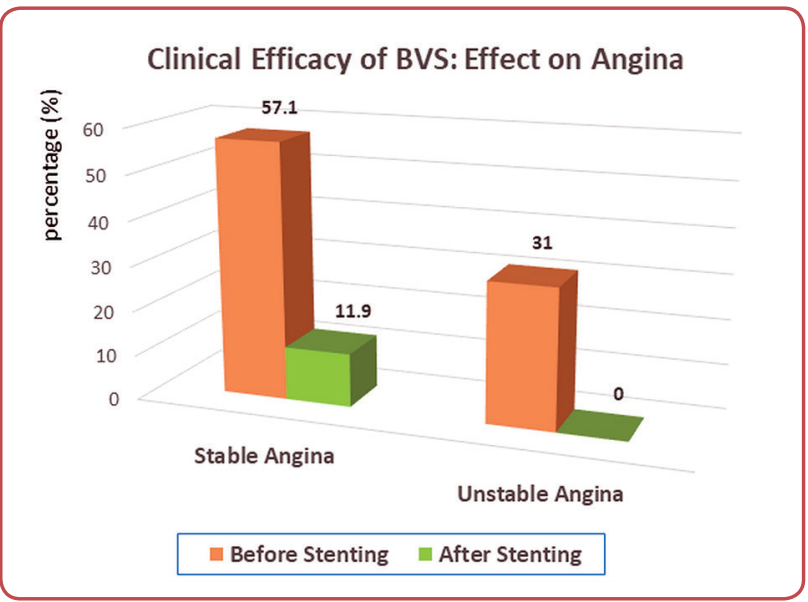

Figure 2: Results of Absorb BVS stenting: Effect on angina pectoris

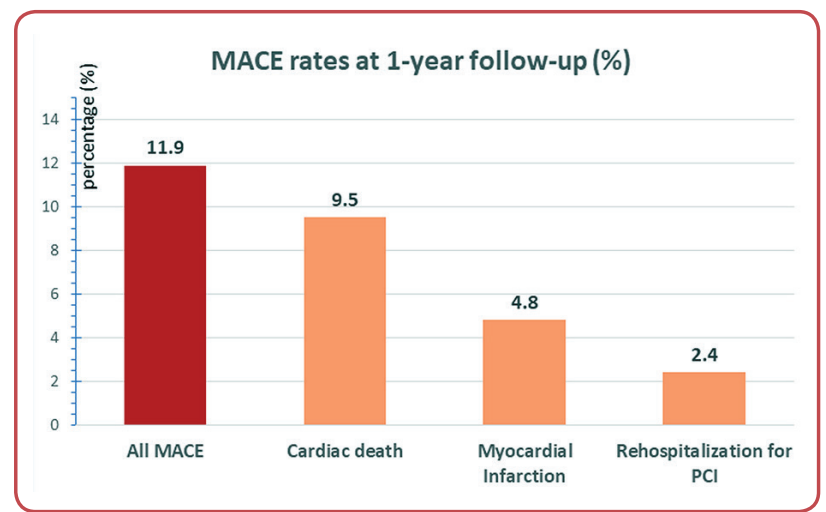

Figure 3: MACE rate at 1 year of follow-up after Absorb BVS stenting

Regarding the mid-term clinical results, at the one-year follow-up, $11.9 \%$ of patients had MACE. Out of all MACE, the most common clinical event 
occurring in $9.5 \%$ of patients was cardiac death; the next one was acute MI (4.8\%), followed by the PCI re-intervention (2.4\%). Overall incidence of MACE and its components at the 12-month follow-up is presented in Figure 3. The average age of patients with MACE was $61.0 \pm 11.4$ and without MACE $57.0 \pm 11.6$ years; statistically nonsignificant difference between these groups related to the age $(t=0.733, p=0.468)$. There were no significant differences related to the patient gender between patients with and without MACE (Fisher's exact test, $\mathrm{p}=0.488$ ) as well.

\section{Discussion}

BVS, compared to metallic stents offer the potential to preserve vascular geometry and function. They provide less alteration of vessels angulation compared to metallic stents and offer a chance for the complete restoration of vascular endothelial function. At 6 to 12- month follow-up, the ABSORB BVS showed improvement in coronary configuration and myocardial function regarding the state before intervention. ${ }^{19}$

Historically, the Igaki-Tamai stent (inventors Dr Keiji Igaki and Dr Hideo Tamai) was the first fully BRS implanted in the human coronary arteries. It was made of poly-l-lactic acid (PLLA) monofilament with a zigzag helical design but without drug elution. ${ }^{20}$ In the late 1990s, a longterm clinical trial (10 years) enrolled fifty patients who were treated with Igaki-Tamai stents. The stent showed a high survival rate, pointing to the efficacy and safety of the device years after implantation. The authors presented that 87 $\%$ of patients survived at ten years and $50 \%$ of them were free from MACE. TLR rate per patient was $16 \%$ after one and three years, $18 \%$ after five years and $28 \%$ after ten years. Two stent thromboses happened during the follow-up period. These stents were not widely used in clinical practice, primarily due to the absence of antiproliferative component. ${ }^{21}$

In humans, Absorb BVS 1.0 (the first-generation device) was evaluated in the ABSORB Cohort A. Clinical five-year follow-up did not show scaffold thrombosis; it showed only one case of MI with the MACE rate of $3.4 \% .^{22,23}$

Absorb BVS 1.1 (the second-generation device) was evaluated in the ABSORB Cohort B and results did not show scaffold thrombosis and cardiac death and the MACE rate was $10 \%$ (at the three-year clinical follow-up). ${ }^{22,24}$

ABSORB EXTEND was initiated as a global prospective research trial including over 800 patients from different locations and with wider range of inclusion criteria (multiple vessels and various lesions). The results of this research showed good efficacy and safety of BVS at threeyear follow-up with MACE rates of $9.2 \%$, TLR rate $10.6 \%$ and scaffold thrombosis rate of 2.2 $\%$, with $1.2 \%$ after one-year of monitoring. ${ }^{25}$

ABSORB-II trial, with one-year follow-up (similar duration as in this study), was a prospective randomised controlled trial aimed to investigate effects of everolimus-eluting BRS comparing to everolimus-eluting DES in the treatment of $d e$ novo coronary lesions (however with the more selective inclusion criteria than in this study). It enrolled approximately 500 patients at 40 sites in Europe and New Zealand. Clinical endpoints included MI, coronary revascularisation, cardiac death, intervention success and anginal status estimated by the Seattle Angina Questionnaire (SAQ). After a year, cumulative rates of angina deterioration and the new angina occurrence were decreased in the BRS group (22\%) vs DES group (30\%), whereas angina status by SAQ was similar. However, in the BRS group, three patients had definite stent thrombosis compared to the DES group with no cases of thrombosis. MACE rate was $5 \%$ vs $3 \%$ (BRS vs DES) and the most common adverse event was MI (14\% vs $1 \%$, respectively). Clinically indicated TLR was $1 \%$ vs $2 \%$, respectively. ${ }^{26,27}$

Stone at al (2019) published a systematic meta-analysis of clinical trials comparing Absorb BVS with DES (everolimus-eluting) encompassing 3,384 patients. Outcomes were analysed throughout five years. A five-year follow-up of BVS implantations showed an increase in rates of TLF in the BVS patients (14.9\% vs $11.6 \%$ ) and stent thrombosis (2.5\% vs $0.8 \%$, respectively). Monitored adverse effects (target vessel-related MI, ischaemia-driven TLR, cardiac death) occurred in $11.6 \%$ of BVS vs $7.9 \%$ of DES until the third year and additional $4.3 \%$ of BVS vs $4.5 \%$ of DES between the third and fifth year. This study has suggested that BVS device might be an admissible alternative to DES in the treatment of coronary artery disease. ${ }^{28}$ 
Three-year clinical outcomes of ABSORB III ${ }^{17}$ trial have revealed that device-related events beyond one year continued to accrue, particularly myocardial infarction and device thrombosis. Multivariate analysis identified reference vessel diameter $<2.25$, prior cardiac intervention and diabetes as predictors of the 3-year device thrombosis. Interestingly, most of the patients with BVS thrombosis were on DAPT at the time of the event.

The current study confirmed the high procedural success rate of Absorb BVS implantation with excellent short-term clinical results (driven by the improvement in anginal status). High completeness of reperfusion rates had opened the expectation on favourable clinical outcomes since it was previously shown that patients with TIMI flow grade $\geq 2$ had better five-year clinical outcome. ${ }^{29,30}$ Furthermore, a significant reduction in the prevalence of stable and unstable angina was obtained following Absorb BVS intervention.

However, 1-year clinical outcomes did not follow the initial success raising concern with Absorb BVS device per se, as well as with proper indications, optimal procedural techniques and the choice and duration of antiplatelet therapy following its implantation.

As a matter of fact, this study had broader inclusion criteria than most of the presented ones, which might account for some of the observed differences in clinical outcomes. Actually, in the current study, the only limitation for patient inclusion, in an essentially all-comers population was the referent vessel size at the targeted lesion less than $2.5 \mathrm{~mm}$. Therefore, the high MACE rate in current research could be attributed to the complex characteristics of the included patients. At the baseline, $90.5 \%$ of patients had dyslipidaemia, while other studies showed lower prevalence, from $7.7 \%{ }^{31}$ to $77.6 \% .^{32}$ Likewise, acute coronary syndromes were present in 54.8 $\%$ of patients and $47.6 \%$ of patients had prior coronary revascularisation (40.5\% PCI and 7.1 $\%$ CABG). However, in the previous studies, few patients with biomarker-positive acute coronary syndromes were enrolled and the rates of prior PCI were much lower, ranging from $1.4 \%$ to 9.2 $\%{ }^{31,32}$ Besides, it was shown in the ABSORB III trial that prior coronary interventions were the independent predictor of device-related adverse events, particularly device thrombosis. ${ }^{17}$
Interestingly, it seems that, in this study, diabetes mellitus did not contribute to the inferior clinical outcome in these patients because its incidence of $33.3 \%$ was comparable with other studies that showed a lower MACE rate. ${ }^{31-33}$ Also, the prevalence of stable and unstable angina at the baseline $(57.1 \%$ and $31.0 \%$, respectively) in treated patients was similar to the available data from the ABSORB III and ABSORB EXTEND clinical trials. ${ }^{17,33}$

Relating to the lesion characteristics in the current study, bifurcations lesions were present in $16.7 \%$. Lesions at coronary bifurcations represent a challenging category of PCI procedures. Hypothetically, BVSs have certain advantages (faster arterial healing and late luminal enlargement) over DES, which makes them suitable for PCI of bifurcations lesions. However, there are overt disadvantages present like struts thickness (150 $\mu \mathrm{m})$, causing disturbance of the local blood flow and increasing the chance of stent thrombosis. ${ }^{17,33}$ Having this in mind, the high rate of bifurcation lesions in the current study could be another contributing factor for the high MACE rate observed.

Concerning the effects of vessel size and procedural technique of BVS implantation on the longterm clinical outcomes, majority of individual studies - including the current one - were not properly sized to evaluate it. However, in a recent large-scale analysis from the major ABSORB studies, Stone has demonstrated that vessel sizing and operator technique were strongly associated with BVS-related outcomes during a 3-year follow-up. ${ }^{34}$

ABSORB IV was a large-scale, randomised, blinded, multicentre trial powered to detect small differences in safety and effectiveness between BVS and everolimus-eluting DES related to procedure techniques and selected population. This study established that 30-day and 1-year clinical outcomes of Absorb BVS can be improved with particular attention to the type of patients and lesions treated and the scaffold implant techniques used. ${ }^{35}$ However, the adverse events in this study continued to occur slightly more frequently with BVS than with DES, mainly driven by BVS thrombosis. ${ }^{35}$ With great interest, it is being awaited whether the 5-year follow-up results of this large study will reveal whether the improved stenting technique will favourably affect the late outcomes. 
Finally, a putative influential factor on the presented results is inclusion of numerous operators in the current study, implying a lower number of stents per individual interventional cardiologist and the consequent slowing down of the learning curve. Besides, it is worth mentioning that the institutional interim adverse events monitoring was not prespecified in the study design.

The present study was, by design, limited to a 12-month follow-up, so it is inappropriate to expand the projections of MACE events beyond one year. However, despite the initial expectations, it was documented in the novel studies that composite adverse event rates continue to accumulate beyond one up to 3-years of follow-up and more frequently than with DES, mainly due to higher rates of BVS thrombosis and myocardial infarction. ${ }^{17}$ AIDA trial reported long-term clinical outcomes of Amsterdam Academic Medical Centre (AMC) registry of Absorb BVS in the patient population reflecting daily clinical practice with up to 4-year follow-up. This registry confirmed also that long-term BVS related adverse events, particularly BVS thrombosis, continued to accure beyond two years after Absorb implantation. ${ }^{36}$ These findings are consistent with the reports obtained by selective optical coherence tomography showing persisting struts even four years after BVS deployment, with the potential to precipitate very late BVS thrombosis. ${ }^{37}$ It is assumed that such late BVS discontinuities with translocation of uncovered strut fragments into the vessel lumen (intraluminal scaffold dismantling) represent one of the main factors responsible for the late BVS thrombosis. ${ }^{17,37}$

To summarise, overall, based on the favourable outcomes of multiple observational research and clinical trials, Absorb BVS was approved by the US Food and Drug Administration (FDA). However, after a relatively brief period of clinical usage, the pooled data of randomised clinical trials showed increased rates of late scaffold thrombosis and MACE compared to the second-generation DES. Related to these data, the FDA issued a warning notice in 2017 and Abbott Vascular stopped selling this device consequently. ${ }^{38}$

To our knowledge, the present research is one of few published reports on the experience with BVS implantation in our region since the clinical application of these scaffolds has been limited to a short period of time, with a limited number of Absorb stents allocated to individual interventional sites.

\section{Conclusion}

Results of the current research demonstrated a high interventional success rate of the Absorb BVS implantation, followed by the early improvement in anginal status. However, that was not translated into favourable mid-term clinical outcomes. Therefore, the later findings strongly support Abbott's decision to recall the current version of Absorb BVS and foster future research on this disruptive innovative technology focusing on the improvement of device design and deployment techniques.

Finally, as a pearl of late wisdom, we point out the importance of an attentive and critical approach when adopting new disruptive technologies in interventional cardiology, with the need for watchful interim monitoring of clinical outcomes and on-the-go readjustment of proper indications and related procedural techniques.

\section{Study limitations}

Current research shares all drawbacks of clinical registries, particularly the broad inclusion criteria allowing inclusion of unstable patients, as well as the involvement of numerous operators with individual approaches to the implantation techniques. At the time of project implementation, presence of dedicated institutional interim adverse events monitoring was not provided as well. Finally, limited sample size and consequently small number of clinical events disabled the use of statistical models to determine uni- and multi-variate predictors of device-related events at the follow-up.

\section{Acknowledgements}

The authors share the highest personal appreciation with all interventional cardiologists from the Dedinje Cardiovascular Institute for their kindness in sharing their work on Absorb BVS implantation to be included in the current publication. 


\section{Conflict of interest}

None.

\section{Abbreviations and Acronyms used}

\author{
ACS - Acute coronary syndrome \\ BRS - Bioresorbable stent \\ BVS - Bioresorbable vascular scaffold \\ BMS - Bare-metal stent \\ CABG - Coronary artery bypass grafting \\ DAPT - Dual antiplatelet therapy \\ DES - Drug-eluting metallic stent \\ FDA - Food and Drug Administration \\ LVEF - Left ventricular ejection fraction \\ MACE - Major adverse cardiovascular events \\ MI - Myocardial infarction \\ PCI - Percutaneous coronary intervention \\ SAQ - Seattle Angina Questionnaire \\ TIMI - Thrombolysis in myocardial infarction \\ TLF - Target lesion failure \\ TLR - Target lesion revascularisation \\ QCA - Quantitative coronary angiography
}

\section{References}

1. Knuuti J, Wijns W, Saraste A, Capodanno D, Barbato E, Funck-Brentano C, et al. 2019 ESC Guidelines for the diagnosis and management of chronic coronary syndromes. Eur Heart J 2020;41(3):407-77.

2. Feinberg J, Nielsen EE, Greenhalgh J, Hounsome J, Sethi NJ, Safi S, et al. Drug-eluting stents versus bare-metal stents for acute coronary syndrome. Cochrane Database Syst Rev 2017;8(8):CD012481. doi: 10.1002/14651858. CD012481.

3. Charpentier E, Barna A, Guillevin L, Juliard JM. Fully bioresorbable drug-eluting coronary scaffolds: A review. Arch Cardiovasc Dis 2015;108(6-7):385-97.

4. Dou Q, Wang W, Wang H, Ma Y, Hai S, Lin X, et al. Prognostic value of frailty in elderly patients with acute coronary syndrome: A systematic review and meta-analysis. BMC Geriatr 2019;19(1):1-10.

5. Valgimigli M, Bueno H, Byrne RA, Collet JP, Costa F, Jeppsson A, et al. 2017 ESC focused update on dual antiplatelet therapy in coronary artery disease developed in collaboration with EACTS. Eur J Cardio-thoracic Surg 2018;53(1):34-78.

6. Cassese S, Byrne RA, Ndrepepa G, Kufner S, Wiebe J, Repp J, et al. Everolimus-eluting bioresorbable vascular scaffolds versus everolimus-eluting metallic stents: A meta-analysis of randomised controlled trials. Lancet 2016;387(10018):537-44.

7. Wiebe J, Hoppmann P, Colleran R, Kufner S, Valeskini M, Cassese $\mathrm{S}$, et al. Long-term clinical outcomes of patients treated with everolimus-eluting bioresorbable stents in routine practice: 2-year results of the ISAR-ABSORB Registry. JACC Cardiovasc Interv 2017;10(12):1222-9.

8. Kraak RP, de Boer HH, Elias J, Ambarus CA, van der Wal $\mathrm{AC}$, de Winter RJ, et al. Coronary artery vessel healing pattern, short and long term, after implantation of the everolimus-eluting bioresorbable vascular scaffold. J Am Heart Assoc 2015;4(11):1-8.

9. Longo G, Granata F, Capodanno D, Ohno Y, Tamburino CI, Capranzano $\mathrm{P}$, et al. Anatomical features and management of bioresorbable vascular scaffolds failure: A case series from the GHOST registry. Catheter Cardiovasc Interv 2015;85(7):1150-61.

10. Gori T, Weissner M, Gönner S, Wendling F, Ullrich H, Ellis $S$, et al. Characteristics, predictors, and mechanisms of thrombosis in coronary bioresorbable scaffolds: differences between early and late events. JACC Cardiovasc Interv 2017;10(23):2363-71.

11. Ellis SG, Steffenino G, Kereiakes DJ, Stone GW, van Geuns RJ, Abizaid A, et al. Clinical, angiographic, and procedural correlates of acute, subacute, and late absorb scaffold thrombosis. JACC Cardiovasc Interv 2017;10(18):180915.

12. Yahagi K, Virmani R, Kesavamoorthy B. Very late scaffold thrombosis of everolimus-eluting bioresorbable scaffold following implantation in STEMI after discontinuation of dual antiplatelet therapy. Cardiovasc Interv Ther 2017;32(1):53-5.

13. Kokkinos PF, Faselis C, Myers J, Narayan P, Sui X, Zhang J, et al. Cardiorespiratory fitness and incidence of major adverse cardiovascular events in US veterans: a cohort study. Mayo Clin Proc 2017;92(1):39-48.

14. Poudel I, Tejpal C, Rashid H, Jahan N. Major adverse cardiovascular events: an inevitable outcome of ST-elevation myocardial infarction? A literature review. Cureus 2019 Jul 30;11(7):e5280. doi: 10.7759/cureus.5280.

15. Keane D, Buis B, Reifart N, Plokker TH, Ernst JM, Mast EG, et al. Clinical and angiographic outcome following implantation of the new less shortening wallstent in aortocoronary vein grafts: introduction of a second generation stent in the clinical arena. J Interv Cardiol 1994;7(6):557-64.

16. Kip KE, Hollabaugh K, Marroquin OC, Williams DO. The problem with composite end points in cardiovascular studies: the story of major adverse cardiac events and percutaneous coronary intervention. J Am Coll Cardiol 2008;51(7):701-7.

17. Kereiakes DJ, Ellis SG, Metzger C, Caputo RP, Rizik DG, Teirstein PS, et al. 3-year clinical outcomes with everolimus-eluting bioresorbable coronary scaffolds: The ABSORB III Trial. J Am Coll Cardiol 2017;70(23):2852-62.

18. Tamai H, Igaki K, Kyo E, Kosuga K, Kawashima A, Matsui $\mathrm{S}$, et al. Initial and 6 month results of biodegradable poly-l-lactic acid coronary stents in humans. Circulation 2000;102(4):399-404.

19. Gomez-Lara J, Brugaletta S, Farooq V, Van Geuns RJ, De Bruyne B, Windecker S, et al. Angiographic geometric changes of the lumen arterial wall after bioresorbable vascular scaffolds and metallic platform stents at 1-year follow-up. JACC Cardiovasc Interv 2011;4(7):789-99.

20. Nishio S, Kosuga K, Igaki K, Okada M, Kyo E, Tsuji T, et al. Long-term ( $>10$ years) clinical outcomes of first-inhuman biodegradable poly-l-lactic acid coronary stents: Igaki-Tamai stents. Circulation 2012;125(19):2343-52.

21. Iqbal J, Onuma Y, Ormiston J, Abizaid A, Waksman R, Serruys P. Bioresorbable scaffolds: Rationale, current status, challenges, and future. Eur Heart J 2014;35(12):76576.

22. Onuma Y, Dudek D, Thuesen L, Webster M, Nieman K, Garcia-Garcia HM, et al. Five-year clinical and functional multislice computed tomography angiographic results 
after coronary implantation of the fully resorbable polymeric everolimus eluting scaffold in patients with de novo coronary artery disease: The absorb cohort a trial. JACC Cardiovasc Interv 2013;6(10):999-1009.

23. Ormiston JA, Serruys PW, Onuma Y, Van Geuns RJ, De Bruyne B, Dudek D, et al. First serial assessment at 6 months and 2 years of the second generation of ABSORB everolimus-eluting bioresorbable vascular scaffold a multi-imaging modality study. Circ Cardiovasc Interv 2012;5(5):620-32.

24. Colombo A, Giannini F. Encouraging data from ABSORB IV pave the way to new scaffolds. Lancet 2018;392(10157):1490-1.

25. Costa JR, Abizaid A, Whitbourn R, Serruys PW, Jepson $\mathrm{N}$, Steinwender C, et al. Three-year clinical outcomes of patients treated with everolimus-eluting bioresorbable vascular scaffolds: Final results of the ABSORB EXTEND trial. Catheter Cardiovasc Interv 2019;93(1):E1-7.

26. Serruys PW, Chevalier B, Dudek D, Cequier A, Carrié D, Iniguez $\mathrm{A}$, et al. $\mathrm{A}$ bioresorbable everolimus-eluting scaffold versus a metallic everolimus-eluting stent for ischaemic heart disease caused by de-novo native coronary artery lesions (ABSORB II): An interim 1-year analysis of clinical and procedural secondary outcomes. Lancet 2015;385(9962):43-54.

27. Diletti R, Serruys PW, Farooq V, Sudhir K, Dorange C, Miquel-Hebert K, et al. ABSORB II randomized controlled trial: A clinical evaluation to compare the safety, efficacy, and performance of the Absorb everolimus-eluting bioresorbable vascular scaffold system against the XIENCE everolimus-eluting coronary stent system in the treatm. Am Heart J 2012;164(5):654-63.

28. Stone GW, Kimura T, Gao R, Kereiakes DJ, Ellis SG, Onuma $\mathrm{Y}$, et al. Time-varying outcomes with the absorb bioresorbable vascular scaffold during 5 year follow-up: a systematic meta-analysis and individual patient data pooled study. JAMA Cardiol 2019;4(12):1261-9.

29. Kim DW, Her SH, Park MW, Cho JS, Kim TS, Kang H, et al. Impact of postprocedural TIMI flow on long-term clinical outcomes in patients with acute myocardial infarction: Five year follow-up results in the Corea-AMI registry. Int Heart J 2017;58(5):674-85.
30. Popović AD, Nesković AN, Babić R, Obradović V, Božinović L, Marinković J, et al. Independent impact of thrombolytic therapy and vessel patency on left ventricular dilation after myocardial infarction. Serial echocardiographic follow-up. Circulation 1994;90(2):800-7.

31. Ganeshkumar AV, Patil RS, Hamid IK. Low major adverse cardiac event rates following bioresorbable vascular scaffold implantation: Impact of implantation technique on treatment outcomes. Indian Heart J 2018;70(1):10-4.

32. Felix CM, Fam JM, Diletti R, Ishibashi Y, Karanasos A, Everaert BRC, et al. Mid- to long-term clinical outcomes of patients treated with the everolimus-eluting bioresorbable vascular scaffold: The BVS Expand Registry. JACC Cardiovasc Interv 2016;9(16):1652-63.

33. Elwany M, Zaki A, Latib A, Testa L, Ielasi A, Piraino D, et al. The impact of the use of bioresorbable vascular scaffolds and drug-coated balloons in coronary bifurcation lesions. Egypt Hear J 2019;71(1):31. doi: 10.1186/ s43044-019-0033-z.

34. Stone GW, Abizaid A, Onuma Y, Seth A, Gao R, Ormiston J, et al. Effect of technique on outcomes following bioresorbable vascular scaffold implantation: analysis from the ABSORB trials. J Am Coll Cardiol 2017;70(23):286374

35. Stone GW, Ellis SG, Gori T, Metzger Dc, Stein B, Erickson $\mathrm{M}$, et al. Blinded outcomes and angina assessment of coronary bioresorbable scaffolds: 30-day and 1-year results from the ABSORB IV randomised trial [published correction appears in Lancet. 2019 Oct 5;394(10205):1230]. Lancet 2018;392(10157):1530-40.

36. Tijssen RYG, Annink ME, Kraak RP, Koch KT, Baan Jr J, Vis MM, et al. The Absorb bioresorbable vascular scaffold in real-world practice: long-term follow-up of the AMC Single Centre Real World PCI Registry. Neth Heart J 2020;28(3):153-60.

37. King SB 3rd, Gogas BD. Can the vanishing stent reappear? Fix the technique, or fix the device? J Am Coll Cardiol 2017;70(23):2875-7.

38. Faxon DP. Absorb bioresorbable scaffolds-out of the woods after 3 years? JAMA Cardiol 2019;4(12):1192-3 